\title{
Analysis on the Characteristics of Buddhism Education and Its Enlightenment to Civic Moral Education
}

\author{
Xiangyong Dong ${ }^{1, *}$ \\ ${ }^{1}$ School of Marxism, Shanghai Ocean University, Shanghai 201306, China \\ *Corresponding author. Email: donxyh@163.com
}

\begin{abstract}
Buddhism education is an indispensable content of Buddhism as a whole. On the one hand, it develops due to the development of Buddhism, and on the other hand, it plays a very important role in the development of Buddhism. Buddhist education has its own purposes and goals, the audience and audience, content and methods. The characteristics of these elements determine the characteristics of Buddhism education and even Buddhism, and their renewal promotes the continuous manifestation of the characteristics of Buddhism education. Corresponding to the manifestation of the characteristics of Buddhism education, its educational function has been continuously optimized, and even has a positive inspiration for the promotion of current civic moral education.
\end{abstract}

Keywords: Buddhism education, Civic morality, Being good.

\section{INTRODUCTION}

As far as the cultural geography is concerned, Buddhism should undoubtedly be classified as an "imported" type compared to China's indigenous ideology, because it is deeply rooted in traditional Indian society - obviously belonging to an alien category. As far as its development is concerned, Buddhism has gained new vitality due to its arrival in China. While achieving its Chinese character, it has also been given a cosmopolitan character. Therefore, compared with its emergence, the follow-up development and trend of Buddhism are more realistic content. It can be said that since Buddhism spread in China, it has undergone a long and complicated process of transformation. It is in this process that its exotic color has been weakened and faded, and finally a new form of Chinese Buddhism has been formed. Looking closely at the formation of Chinese Buddhism, it is not difficult to find that Buddhism education plays a very prominent role in it. Except for those who promote the Dharma and the method of enlightenment, they

*Project: The Humanities and Social Science Research Planning Fund Project of the Ministry of Education "Research on the Philosophical Principles of Traditional Ritual and Music" (19YJA720003) all rely on Buddhism education to be realized. In a sense, it can be said that the Sinicization of Buddhism is the process in which Buddhism continues to grow in China through Buddhist education. This determines that Chinese Buddhism inevitably contains rich Buddhist educational thoughts, and this "containment" is not static. On the contrary, its dynamic meaning is a more critical dimension. On the one hand, it has played a role in the formation of Chinese Buddhism and enriched itself. On the other hand, in keeping with the pace of the development of the times, Buddhist education will naturally continue to be enriched. Of course, as indicated by the law of negation, twists and turns are inevitable in the development of anything. In keeping with the "transformation" of Buddhism in China, Chinese Buddhist education has undergone several twists and turns. The socalled "trough" is even more frequent. However, the development of Chinese Buddhism to the present "climate" fully demonstrates the value of relevant Buddhist education. Especially in the current society, the urgency of improving civic moral literacy has become increasingly prominent, and the re-advancement of civic moral education has become a necessity. In this "re-advance" effort, 
the concepts, methods and practices of Buddhist education can undoubtedly serve as an important reference, which can positively inspire the in-depth promotion of civic moral education.

\section{PURPOSE AND GOAL LEVEL BASED ON PROMOTING PEOPLE TO DO GOOD}

The purpose of education is to promote the growth and development of people. As one of the specific aspects of education, Buddhist education also pays attention to people and their development. The practice of Buddhist education in China has always revolved around the development of people and people, and is first implemented and embodied in the continuous renewal of educational purposes and goals, thus gradually forming its own characteristics. In the contemporary society with increasing humanistic consciousness, Buddhist education pays attention to people and their development, and its reference is self-evident. Specifically, in terms of civic moral education, relevant purposes and goals are also positive.

Just like Émile Durkheim's position, compared with other religions, Buddhism "doesn't have to consider whether there is a god at all"[1]39. Even if the existence of God is accepted as a fact, it will focus more on the "progress" of this life. Although Durkheim's argument may lead to different conclusions due to different interpretation angles, one thing is certain - it is basically in line with the educational purpose of Buddhism, that is, people can strive to become Buddhas through appropriate channels not relying on the help of God, but through actual self-efforts. As it know to all, in the process of formation and development of Chinese Buddhism, its internal divisions are divided into different sects or sects. However, it is inevitable that different sects will be questioned. There are also various views on the issue of Buddhahood, and there are many tensions and even oppositions among the various positions, but it is the common adherence to regard becoming a good Buddha as the fundamental purpose of Buddhism education. Regardless of whether some people can become Buddhas and everyone can become Buddhas, or the sudden-gradual disputes over the question of becoming Buddhas have evolved into suddengradual mutual understanding, the focus is undoubtedly that people can become Buddhas, and it has always been based on the upholding of becoming Buddhas by virtue. Affirming that people can become Buddhas, and that they can be realized through real struggle in this life, constitutes the fundamental purpose of Buddhist education. It is precisely because of this purpose that the necessity of Buddhist education can be enriched and manifested. It can even be said that the purpose that people can become Buddhas from good is the logical starting point of Buddhist education.

As for the goal of Buddhism education, it is to guide people to become Buddhas through practising for good in this life through the specific practice of Buddhism education. It is not difficult to find that the goal is the logical extension of the purpose, that is, on the premise that the fundamental purpose affirms that people can become good Buddhas. And the goal setting answers in general, through Buddhism education to guide people to become a good Buddha. As far as Chinese Buddhism education is concerned, on the basis of the continuous renewal of ideas, the specific goals also show corresponding historicality. Among them, it is worth highlighting that it is constantly weakening at the level of the other side. On the contrary, the emphasis on the pursuit and struggle for good in this life is the basic trend from the perspective of consensus. In view of the current reality, it is precisely because of the strengthening of the struggle in the world that Chinese Buddhist education has achieved unprecedented practicality. And this practicability in turn encourages people to implement the pursuit of good in this life, which will undoubtedly contribute to the fulfillment of the goals of Buddhist education. In fact, from concepts such as "Humanistic Buddhism", one can clearly see the transformation of the goals of Buddhist education, because once humanity is taken as the basic limitation of Buddhism, those who oppose or contradict the world are of course excluded from the category of Buddhist nature. In this way, it means that Buddhism's practice and practice for good are based on and seen in the current world, and Buddhism education based on concepts such as "Humanistic Buddhism" will obviously have a lot to do in guiding people's practice in this life.

The in-depth promotion of civic moral education at present, in terms of purpose and goals, the enlightenment that can be obtained from Buddhist education is focused on acknowledging that people can be good and can lead people to good. First of all, for any person who exists as a social reality, it must be recognized that they can be good and pursue good. Of course, it must be pointed out that the minimum recognition that this pair of people can ask for good and benevolence does not mean denying the existence of unkind or 
unscrupulous people in reality. On the contrary, unkind or unscrupulous people are inevitable in any society. More importantly, non-kindness or lack of virtue constitutes a practical starting point for goodness and seeking goodness. Just as Buddhist education insists that people can become Buddhas, civic moral education should undoubtedly firmly believe that the people can be good and virtuous, and take it as the corresponding purpose. Secondly, the goal of civic moral education is undoubtedly to guide the people to be good, and Buddhism education's protruding of the world's endeavors will enhance the reality of this goal, and there is no lack of inspiration for its ideas. Especially, it is necessary to abandon the influence of certain thinking in contemporary society. The goal of civic moral education must weaken idealism and other colors, and focus on guiding the people to strive for good through the world, mold oneself into a virtuous citizen, and strive to achieve one's own value and be good at society on the basis of not despising the reality and therefore not despising life through the determination to be a good person and practice good deeds. Therefore, it may be said that rich virtue is only the general meaning of the goal of civic moral education, and it is its deep meaning to enable society (including any individual) to have the best state of existence due to virtue.

In summary, the purpose and goal of Buddhist education are closely related. Purpose is an important prerequisite for determining the goal, and in a sense, the goal is the concretization of the purpose. The reason of Buddhism education affirms that people can be good to become Buddhas, and its goal is to guide people to become Buddhas, which typically reflects the characteristics of the "relationship" between the two. In the process of advancing the construction of civic morality, the purpose and goal of Buddhist education and the "relation" between the two have important reference meanings for civic moral education, and first of all, it is embodied in the strengthening of the purpose of civic moral education that people can be good and the goal is to effectively guide people to good.

\section{AT THE LEVEL OF THE IMPARTERS AND THE RECEIVERS, IT FOCUSES ON MAKING PEOPLE CLEAR AND GOOD}

If the analysis of the purpose and goal focuses on answering "why should Buddhist education be carried out", then the examination of its imparters and receivers is intended to clarify the problems of "who conducts Buddhist education" and "to whom Buddhist education is carried out". In the formation and development of Chinese Buddhism education, whether it is for the imparters or the receivers, it has a certain historical significance. And overall, due to continuous development, it has become more "reasonable" (both the principles of Buddhism and thinking), which undoubtedly has positive significance for the consideration of civic moral education in related aspects.

The category of "imparters" here means the person who teaches. If it is specific to Buddhist education, it refers to the person who spreads Buddhism. Although it has the meaning of being written by its meaning, as far as it is homophonous with "receivers" in Chinese pronunciation, the word "imparters" is inevitably appropriate. The imparters of Chinese Buddhism education is equivalent to monasteries in a long historical period. In other words, Buddhism education is carried out by monasteries and their monks. While it has the depth of benefits and the simplicity of belief, it has gradually exposed the corresponding limitations. Especially after the curtain of modern history has been opened, the expansion of Buddhist education imparters has become inevitable and necessary. This expansion is mainly achieved through three ways: the first is the conscious transformation of the role of temples, which is typically reflected in the establishment of Buddhist academies at all levels. They not only inherit the traditional temple's promotion of goodness in Buddhism education, but also form their own characteristics in the exploration of Buddhism education; The second is that the lay group has become an important component of Buddhist education imparters, which not only conforms to the legal principle of layman's "protecting the law", and in a sense reflects the success of the imparter's "giving to the public", but also correspondingly strengthens the realistic appeal of Buddhist education to make people aware of goodness; third, secular education organizations have gradually invested in Buddhist education, such as related Buddhist research and educational institutions in colleges and universities. This certainly reflects the feelings of secular education, but it also shows the socialization of Buddhist education from the side. At this point, it can be said that with the development of Buddhism education, its imparters are becoming more diverse and complex. Even if this kind of expansion does not lack room for further improvement, the active 
promotion of people's understanding of goodness is the main function of the expansion of the imparters.

The receivers of Buddhist education refer to its recipients, and its meaning is obviously easier to understand than "imparters". According to the attitude of Buddhist education recipients towards Buddhism, it can be basically divided into three levels. Buddhist monks are at the first level. If they are a monk and live as a monk, they receive a Buddhist education and understand that they are good. This is determined by the nature of the inheritance of Buddhism. It is precisely because of this characteristic that the education of monks has always occupied an extremely important position. Correspondingly, the content and methods of Buddhist education are basically "born" according to their needs. The second level of the Buddhist education audience is the layman. Compared with the education of the monks, the education of the layman is inevitably at a disadvantage, and even has been quite lacking in strength. Since modern times, the education of laymen has gradually received due attention. One is that as a power of Buddhism faith in the world, the layman has a great and wide-ranging social influence that other powers cannot match. Except for monks and laymen, all living beings in the secular world constitute the third level of the audience of Buddhist education in a certain sense. Although they don't believe in Buddhism, their concepts and behaviors are often susceptible to them, which gives them opportunities for spiritual detachment and self-examination. Moreover, the receivers is not equal to the believers, so ordinary people who do not believe in Buddhism should be regarded as the receivers in a broad sense, so that they can choose the "convenience" when they are understanding good and being good.

Not only is a specific type of education, civic moral education also has its imparters and receivers. The expansion and diversified characteristics of Buddhist education in related aspects have inspired the former to improve the current society in many ways. First, from the perspective of the imparters, on the one hand, the main body of the implementation of civic moral education often still has the limitation of weak sociality, and the tendency of simplification and the lack of sense of hierarchy coexist. Although it has been repeatedly emphasized that civic moral education should be socialized, correspondingly powerful social entities have never appeared. Therefore, how to cultivate social organizations that can undertake the responsibilities of civic moral education is the practical focus of civic moral education; on the other hand, the promotion of civic moral education also relies on the "moral teachers" among the ordinary people, that is to say, it is a must to strive to cultivate moral education imparters among ordinary people, so that they can play a role similar to that of laymen in promoting people's goodness in Buddhist education. Secondly, from the perspective of the audience, it is like Buddhism and the path to becoming a Buddha is constantly extinct. Even those who are the least likely to become a Buddha should guide them to understand goodness and strive to become a Buddha. The actual implementation of civic moral education must target all the people in society, and it is firmly believed that this way can make all people understand the good. It is necessary to abandon the horizontal differences of regions and other aspects, but also to break the vertical differences of classes, so that the people can enjoy civic moral education and survive and live better due to the improvement of their own moral quality.

In other words, the expansion of Buddhist education imparters provides inexhaustible support for the development of Buddhism, and the continuous progress of its audience is a powerful indicator of the effectiveness of Buddhist education. In particular, the receivers' tendency to "be imparters" highlights the key to the continuation and breakthrough of Buddhist education. The characteristics of Buddhism education in the imparters and the receivers have many meanings to the current social civic moral education. However, whether it is to expand imparters or focus on the progress of the receivers, it should be subordinated to the foundation of enhancing the effectiveness of civic moral education.

\section{FOCUSING ON HELPING OTHERS TO BE GOOD AT THE CONTENT AND METHOD LEVEL}

As far as complete Buddhist education is concerned, "what education to use" and "how to teach" are undoubtedly the organic components of it, and it is the most realistic element in the development of Buddhist education. Otherwise, the aforementioned two aspects will lose their value because they become empty talk. "What education to use" means to question the content of Buddhist education, while "how to teach" is to question its specific methods. However, no matter the content or the method, Buddhist education has its own 
characteristics, and these characteristic content and methods also constitute an important reference for the current civic moral education.

The content of Buddhism education is very complicated. On the one hand, it is self-evident in terms of its breadth and connotation, which can be seen from the accomplishments of many eminent monks. On the other hand, it is also undergoing changes in the historical development, which fully embodies the characteristics of changing over time. First of all, the "three studies" composed of precept, concentration, and wisdom cover the numerous methods of Buddhism and are the core part of all Buddhist teachings. Even though the specific content of Buddhism's "three studies" is constantly changing, and it is not ruled out that some content is no longer alive due to unintentional opportunities, the "three studies" of Buddhism, precept, concentration, and wisdom as a whole have always been the fundamental content of Buddhism and the basic aspect of Buddhist education to help others be good. Or it can be said that it is precisely with the teaching of the "three studies" as the first task that Buddhist education can exist as a unique specific educational form. Secondly, in the development of Chinese Buddhism, the tendency of Buddhism to be ethical is very prominent, which is naturally also reflected in the content of Buddhist education, in fact adding to the content of Buddhist education the atmosphere of integrating into the Middle-earth society. And this kind of atmosphere has also been extended to the present, becoming an important entry point for Buddhism to contribute to education and serve the society. Thirdly, the emphasis on the breadth of knowledge in the content of modern Buddhist education has also become a major feature of its own. It shows the modern temperament of Buddhism, which will certainly be of great benefit to improving the social viability of Buddhism.

The method of Buddhist education is related to the complexity inherent in the process of Sinicization of Buddhism, and it also shows the characteristics of complexity and variety. There are even considerable conflicts between some methods, but it does not prevent the Buddhist education as a whole from being harmonious at the method level, and the result does not diminish the merits of helping others for good, and the author chooses the typical ones for analysis here. First, Buddhist education attaches great importance to the role of role models. The Lord Buddha is a practitioner of Buddhist education by example, and later generations of eminent monks have also taken the lead in setting examples in the education process, highlighting example and teaching to help others in the process of education. "Showing" the Dharma with the body in this way, in addition to being more realistic, its actual effect is also greatly enhanced; Second, Buddhist education emphasizes both learning and doing in methods. On the one hand, it continuously strengthens the study of Buddhist theories, so as to continuously purify the inner world of the audience to make them good. On the other hand, it also highlights the importance of practicing practically. Practice is an indispensable link for the realization of Buddhahood. To do good afterwards is the key. Through the simultaneous advancement of learning and practice, both internal and external practice and meditation can be achieved simultaneously; third, the lifelization of Buddhism education can be called the pioneering work of Chinese Buddhism. Regardless of whether it is a close relationship between college education and jungle education, or advocating the simultaneous cultivation of Zen and farmers, or even the late Master Jinghui advocated "Life is Zen, Zen is life"[2]126. If it is specific to Buddhist education, they all emphasize the implementation of Buddhist education in daily life and the spread of life in Buddhist education.

When coming to civic moral education, the content and methods are different from Buddhist education. This is undeniable. However, it is also undeniable that it can absorb valuable factors from the latter, so as to continuously improve its content and methods. In terms of the content of civic moral education, it is necessary to not only excavate the traditional moral materials of the nation, promote the modern transformation of excellent spiritual resources including Buddhism, and to enhance the sense of proximity of civic moral education due to cultural commonality, but also expand the field radiated by moral factors. As the ethicalization of Buddhism in China makes clear, efforts must be made to incorporate moral factors such as moral consciousness and moral materials into all possible knowledge education, so that knowledge education can serve civic moral education. In terms of the methods of civic moral education, the most urgent problem to be solved is to weaken the color of preaching. Because it has been proved to be a typical method with half the effort, the pluralism of advocacy methods is the reality. For example, it is necessary to attach importance to the demonstration power of good morals and highlight the role of example; people can learn from Buddhist education to pay equal attention to learning and practice, and 
appropriately enhance the status of moral practice in civic moral education, and stay away from badly influential people; it is also a necessity to implement civic moral education in daily life, avoid staged artificial advancement, and make civic moral education "moisturize things silently", and truly do it in daily life without knowing it.

In summary, the continuous update of Buddhist education content, without conflicting with the basic core of Buddhism, is more adapted to the development of the times, making Buddhism a spiritual form of real development. And in connection with the update of related content, the methods of Buddhist education have also undergone optimization, and it is not even ruled out to ask for methods from life. For the current civic moral education, on the one hand, of course, valuable elements can be drawn from the content and methods of Buddhist education, and on the other hand, it should be inspired by thinking from its continuous update and development.

\section{CONCLUSION}

In short, as a supporting element of the development process of Buddhism, Buddhism education itself must be renewed by the development of Buddhism. Of course, the continuous renewal of Buddhist education is not based on pure negation. On the contrary, the excellent and substantive parts of it are first carried forward in the renewal, and the negative definition of renewal focuses on the "abandonment" of the value that has been lost. Buddhism education, which has undergone renewal and continuous development, is more legitimate in terms of purpose and goals, more reasonable in terms of imparters and receivers, and more reasonable in content and methods. This three "reasonable" will certainly provide impetus for the deeper and healthy development of Buddhist education. The continuously updated Buddhist education can not only promote the development of Buddhism as a whole, but also provide important reference for the promotion of civic moral education. These references are not only for the purpose and goal, but also for the imparters and receivers, and it is more about the content and methods. But it must be admitted that, due to the developmental nature of education, there is still a lot of room for in-depth exploration in how to maximize the effectiveness of these references.

\section{AUTHORS' CONTRIBUTIONS}

This paper is independently completed by Xiangyong Dong.

\section{REFERENCES}

[1] (France) Émile Durkheim, Les formes élementaires de la vie religieuse (The basic forms of religious life)[M]. Qu Dong, Ji Zhe, trans. Beijing: The Commercial Press, 2011. (in Chinese)

[2] Master Jinghui, Introduction to Zen [M]. Shanghai: East China Normal University, 2013. (in Chinese)

[3] Shi Yinshun, Collected Essays on Earthly Buddhism [M]. Beijing: Zhonghua Book Company, 2010. (in Chinese)

[4] Ding Gang, Chinese Buddhism Education: A Comparative Study of Confucianism, Buddhism and Taoism Education [M]. Chengdu: Sichuan Education Press, 2010. (in Chinese)

[5] Lv Cheng, A Brief Introduction to the Origin of Chinese Buddhism [M]. Beijing: Zhonghua Book Company, 1979. (in Chinese)

[6] Luo Guojie, Ethics (revised edition) [M]. Beijing: People's Publishing House, 2014. (in Chinese) 